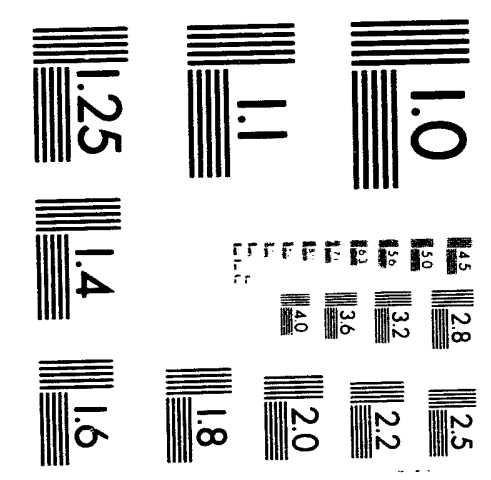



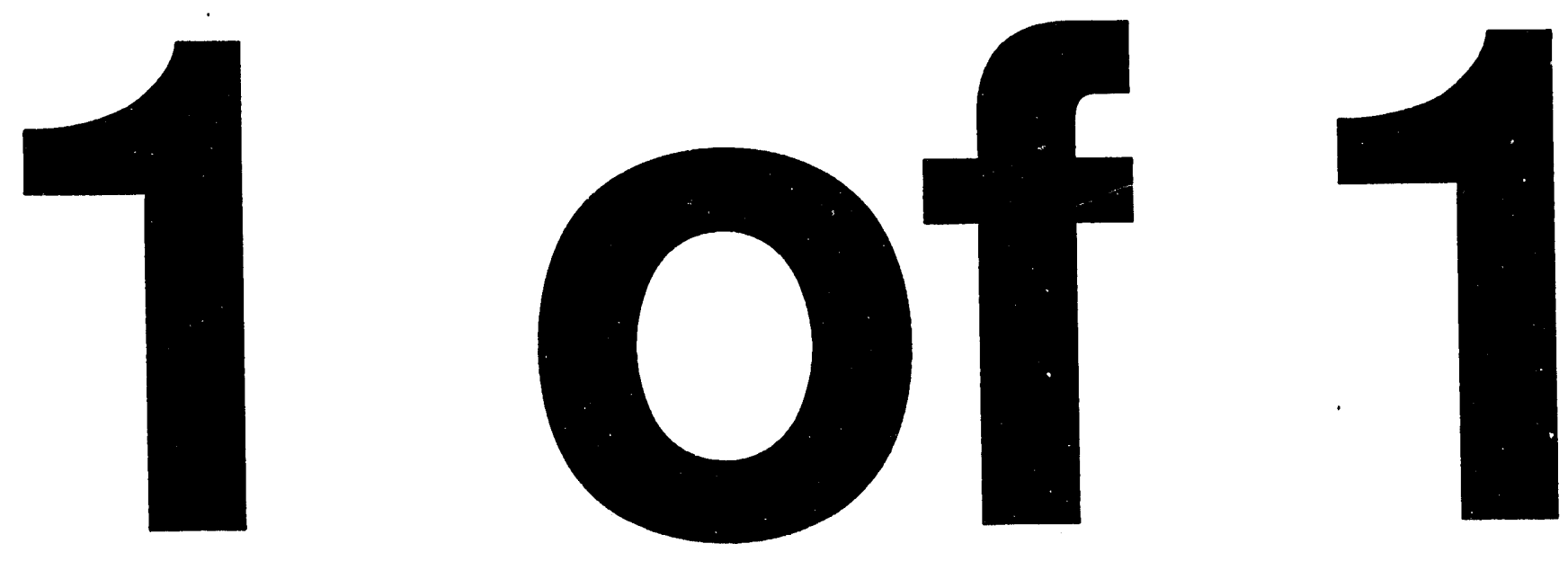


\title{
BINDING OF COPPER AND NICKEL TO CAVITIES IN SILICON FORMED BY HELIUM ION IMPLANTATION
}

S.M. MYERS, D.M. FOLLSTAEDT, AND D.M. BISHOP

Semiconductor Physics Dept. 1112, Sandia National Laboratories, Albuquerque, NM 87185-1056

\begin{abstract}
Cavities formed in $\mathrm{Si}$ by $\mathrm{He}$ ion implantation and annealing are shown be strong traps for $\mathrm{Cu}$ and $\mathrm{Ni}$ impurities. Experiments utilizing ion-beam analysis and transmission electron microscopy indicate that $\mathrm{Cu}$ is trapped at the internal surfaces of cavities up to $\approx 1$ monolayer coverage with a binding energy of $2.2 \pm 0.2 \mathrm{eV}$ relative to solution. This is greater than the heat of solution from the precipitated $\mathrm{Cu}_{3} \mathrm{Si}$ phase, detern ied to be $1.7 \mathrm{eV}$ in agreement with earlier work. Copper at cavity-wall sites is reversibly replaced by $\mathrm{H}$ during heating in $\mathrm{H}_{2}$ gas, indicating the relative stability of the two surface terminations. Initial results for $\mathrm{Ni}$ impurities indicate that trapping at cavities is again energetically preferred to silicide formation. The saturation coverage of $\mathrm{Ni}$ on the internal surfaces, however, is an order of magnitude smaller for $\mathrm{Ni}$ than $\mathrm{Cu}$, consistent with published studies of external-surface adsorption. These results suggest that cavity trapping may getter metallic impurities in Si more effectively than methods based on silicide precipitation.
\end{abstract}

\section{INTRODUCTION}

Transition-metal impurities are extremely detrimental in Si-based microelectronics, introducing deep levels into the band gap and precipitating at such undesirable locations as Si$\mathrm{SiO}_{2}$ interfaces. Moreover, becaúse these elements are highly mobile in $\mathrm{Si}$, growing precipitates can draw metal atoms from a macroscopic wafer volume. (For a review, see Ref. 1.) The concern with $\mathrm{Cu}$ impurities in particular is amplified by the prospect of $\mathrm{Cu}$ metallization in devices [2]. In device production, stringent clean-room procedures are supplemented by gettering, a procedure whereby metal impurities are tied up in sacrificial regions of the wafer. Gettering is most often accomplished by introducing imperfections such as $\mathrm{SiO}_{2}$ precipitates and lattice defects, which nucleate silicide precipitation [1]. Also used is P doping, believed to enhance the solubility of the impurity in the doped region [1]. Ion implantation has been an important tool for the introduction of gettering centers for more than 20 years. (See, e.g., Ref. 3.)

In the present work we mechanistically investigated the trapping of two transition metals, $\mathrm{Cu}$ and $\mathrm{Ni}$, at the internal surfaces of cavities formed in $\mathrm{Si}$ by $\mathrm{He}$ ion implantation and annealing. Particular attention was given to the strength of trapping and the number of binding sites. Internal surfaces are highly reactive due to the Si dangling orbitals and may bind metal impurities even more strongly than precipitates of the metal silicide phases. Furthermore, while second-phase precipitation reduces the solution concentration to a characteristic solid solubility and no further, the influence of static traps such as surface dangling bonds should persist to arbitrarily small concentrations. Therefore, cavity traps may provide an attractive alternative for gettering. While the structures of transition-metal adsorbates on external $\mathrm{Si}$ surfaces have been investigated extensively, with detailed information being available for both $\mathrm{Cu}[4,5]$ and $\mathrm{Ni}[6,7]$, quantitative information on binding energies relative to solution and to the silicide phases was lacking before the present study. The results reported here are final in the case of $\mathrm{Cu}$ but preliminary for $\mathrm{Ni}$. 


\section{METHOD}

Cavities were formed in $\mathrm{Si}$ by ion implanting $\mathrm{He}$ at room temperature and then vacuum annealing at 700 or $900^{\circ} \mathrm{C}$, a procedure similar to one reported previously [8]. The anneal caused release of the $\mathrm{He}$ from the $\mathrm{Si}[8]$, removed implantation damage, and enlarged the cavities. Copper and $\mathrm{Ni}$ were then introduced by ion implantation, and precipitation of the respective equilibrium silicides was induced by annealing. The interactions of the metal solutes with the cavities in such specimens were examined by positioning the cavity and silicide layers at different depths and observing the internal redistributions of the $\mathrm{Cu}$ or $\mathrm{Ni}$ by Rutherford backscattering spectrometry (RBS). In experiments involving $\mathrm{H}$, the deuterium isotope was employed and profiled using the ion-beam-induced nuclear reaction ${ }^{2} \mathrm{H}\left({ }^{3} \mathrm{He},{ }^{1} \mathrm{H}\right){ }^{4} \mathrm{He}$ [9]. The microstructure of the cavities was determined using transmission electron microscopy (TEM), and the presence of the $\mathrm{Cu}_{3} \mathrm{Si}$ phase was demonstrated by transmission electron diffraction as discussed elsewhere [10].

To extract binding energies from the above experiments, we numerically solved the coupled differential equations which describe diffusion accompanied by reversible trapping and second-phase precipitation and adjusted the binding energies to produce agreement with the data. The methodology of such calculations has been described elsewhere [11] and will not be repeated here. Instead, to convey the physical basis of the analysis, we present simplified equations that approximately describe the two types of experiment reported in the following section. The first of these is the transport of metal atoms from a silicide phase at one depth to cavity traps at another depth. If the traps are sufficiently strong to be regarded as irreversible, and if the cavity and silicide layers are assumed to have negligible thickness and to be separated in depth by $\Delta x$, then the steady-state diffusion flux, $\Phi$, is given by

$$
\Phi \approx \mathrm{n}_{\mathrm{S}} \mathrm{D} / \Delta \mathrm{x}
$$

where $n_{S}$ is the solubility of the metal in equilibrium with the silicide phase expressed as atomic density and $\mathrm{D}$ is the diffusion coefficient. When the diffusion coefficient in Eq. (1) is taken from the literature, the measured redistribution flux gives the solubility, and the temperature dependence of this solubility then determines the heat of solution from the silicide phase.

The second type of experiment involves redistribution between two cavity layers, one initially saturated with metal atoms and the other initially unoccupied. The ralistribution leads ultimately to equal fractional occupations of traps in the two layers. The $\mathrm{kix}$ / $\mathrm{f}$ metal dtoms, with simplifying assumptions similar to those made above, is

$$
\Phi \approx\left[\mathrm{n}_{\mathrm{c}}\left(\theta_{1}\right)-\mathrm{n}_{\mathrm{c}}\left(\theta_{2}\right)\right] \mathrm{D} / \Delta \mathrm{x}
$$

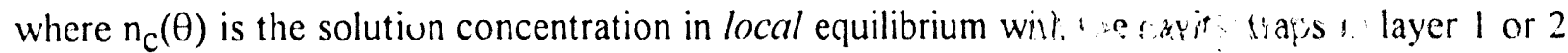
and $\theta$ is the fractional occupancy of the trapping sites. The quantity $n_{c}$ is ves by

$$
\mathrm{n}_{\mathrm{c}}(\theta) / \mathrm{N}_{\mathrm{s}} \approx[\theta /(1-\theta)] \exp \left(-\mathrm{E}_{\mathrm{c}} / \mathrm{kT}\right)
$$

where $N_{S}$ is the temperature-independent atomic density of solution sitis and $E_{c}$ is the trap binding energy relative to solution. Hence, the experimentally measured flux $\Phi$ is sensitive to the binding energy. 


\section{RESULTS AND INTERPRETATION}

Figure 1 shows a cross-section TEM image of cavities formed by implanting $10^{17} \mathrm{He} / \mathrm{cm}^{2}$ at room temperature and $30 \mathrm{keV}$ and then vacuum annealing for $30 \mathrm{~min}$ at $700^{\circ} \mathrm{C}$. Detailed analysis of such images indicates that the average cavity diameter is $8 \mathrm{~nm}$ and that the ratio of internal surface area to wafer area is $6.7 \pm 1.2$. The latter number implies that there are $\approx 5 \times 10^{15}$ $\mathrm{Si}$ atoms on the internal surfaces per $\mathrm{cm}^{2}$ of wafer area. The cavities are faceted, with (111) faces predominating followed in order by $(100)$ and (110) [12].

The binding of $\mathrm{Cu}$ to such cavities was demonstrated by forming the equilibrium silicide $\eta-\mathrm{Cu}_{3} \mathrm{Si}$ on the opposite side of the $250-\mu \mathrm{m}$ thick Si sample and then observing the diffusion of $\mathrm{Cu}$ from the silicide across the wafer to the cavities during vacuum annealing. The silicide was introduced by implanting $10^{17} \mathrm{Cu} / \mathrm{cm}^{2}$ at $150 \mathrm{keV}$ and then annealing at $600^{\circ} \mathrm{C}$, and its presence was demonstrated by transmission electron diffraction [10]. During more extended annealing at $600^{\circ} \mathrm{C}$, the silicide partially dissolved and the $\mathrm{Cu}$ diffused to the cavities until the associated internal surfaces were saturated. The saturation depth profile of $\mathrm{Cu}$, as measured from the cavity side of the specimen, is given by open circles in Fig. 2 . The consistency of the profile with the depth distribution of cavities is apparent. The saturation areal density of $\mathrm{Cu}$ in the cavity layer is $5 \times 10^{15} \mathrm{~cm}^{-2}$, corresponding to about one monolayer on the internal surfaces.

When the dose of implanted $\mathrm{He}$ was reduced to $2 \times 10^{16} \mathrm{~cm}^{-2}$, TEM showed that the cavities were several times fewer in number and restricted to a narrower band about the peak $\mathrm{He}$ concentration, whereas at a dose of $1 \times 10^{16} \mathrm{He} / \mathrm{cm}^{2}$ the:: were only a few isolated cavities. The saturation depth profiles for these cases are included in Fig. 2 and are seen to reflect the variations in observed microstructure. The cavity microstructure was also changed by annealing at $900^{\circ} \mathrm{C}$ for $1 \mathrm{hr}$ instead of $30 \mathrm{~min}$ at $700^{\circ} \mathrm{C}$ after implanting $\quad 10^{17}$ $\mathrm{He} / \mathrm{cm}^{2}$. The cavities were then observed to be larger, with an average diameter of about $20 \mathrm{~nm}$, and fewer in number, leading to a

Fig. 1. Cross-section TEM of cavities in Si. The depth scale conforms to that of Fig. 2.
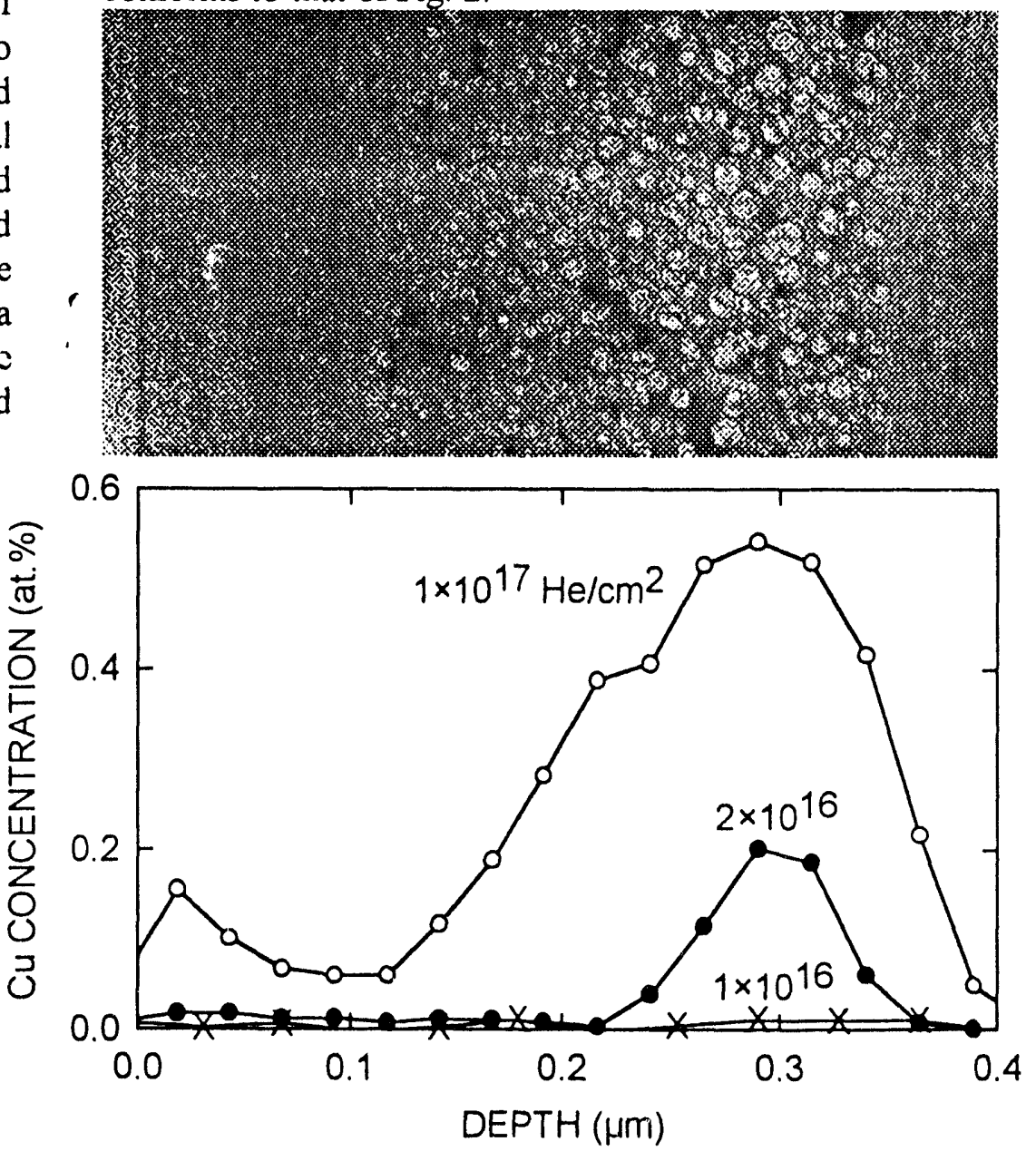

Fig.2. Saturation depth profiles of $\mathrm{Cu}$ in cavities. 
reduction of about $50 \%$ in the internal surface area. Consistent with this change, the saturation areal density of $\mathrm{Cu}$ decreased to $2.3 \times 10^{15}$ $\mathrm{cm}^{-2}$. These comparisons reinforce the view that the trapped $\mathrm{Cu}$ is indeed occupying surface sites on the cavity walls.

The transfer of $\mathrm{Cu}$ from the silicide to the cavity layer demonstrates that the binding on the internal surfaces is more stable. To quantify the respective binding energies, we examined

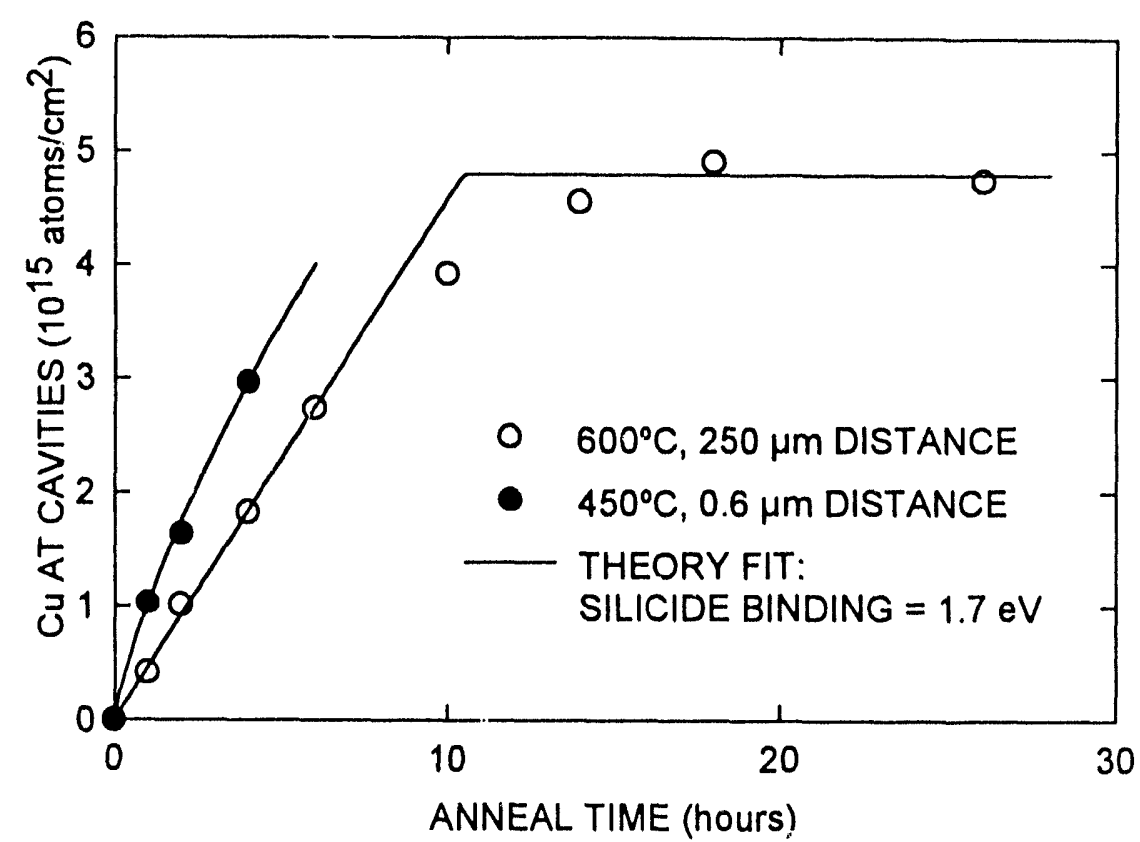

Fig. 3. Redistribution of $\mathrm{Cu}$ from $\mathrm{Cu}_{3} \mathrm{Si}$ to cavities.

the rates of internal $\mathrm{Cu}$ redistribution in multilayered specimens as outlined in the preceding section. For example, Fig. 3 shows the accumulation of $\mathrm{Cu}$ in cavities resulting from silicide dissolution under two conditions. In one of these, the $\mathrm{Cu}_{3} \mathrm{Si}$ and cavities were on opposite sides of the wafer and separated by $250 \mu \mathrm{m}$, and the isothermal annealing was performed at $600^{\circ} \mathrm{C}$. In the other case, the silicide and cavity layers were on the same side of the wafer and were respectively centered at 0.1 and $0.7 \mu \mathrm{m}$, so that the separation was $\approx 0.6 \mu \mathrm{m}$. The resulting much smaller value of $\Delta \mathrm{x}$ in Eq. (1) was offset by performing the isothermal anneals at the lower temperature of $450^{\circ} \mathrm{C}$, where the solubility $n_{\mathrm{S}}$ and diffusion coefficient $\mathrm{D}$ are greatly reduced, so that the rate of $\mathrm{Cu}$ redistribution was comparable at the two temperatures. The theoretical curves in Fig. 3 were obtained by solving the diffusion-trapping-precipitation formalism of Ref. 11, using the published diffusion coefficient for $\mathrm{Cu}$ in $\mathrm{Si}$ [13] and adjusting the solubilities at 450 and $600^{\circ} \mathrm{C}$ to produce agreement with experiment. The fitted solubilities are $1.7 \times 10^{12} \mathrm{~cm}^{-3}$ at $450^{\circ} \mathrm{C}$ and $2.0 \times 10^{14} \mathrm{~cm}^{-3}$ at $600^{\circ} \mathrm{C}$, giving a solution activation energy of $1.73 \mathrm{eV}$, in good agreement with earlier studies of $\mathrm{Si}-\mathrm{Cu}_{3} \mathrm{Si}$ equilibrium above $650^{\circ} \mathrm{C}$ [14].

To determine the binding energy for $\mathrm{Cu}$ in cavity traps, samples were prepared with two cavity layers, one initially saturated with $\mathrm{Cu}$ and the other initialiy unoccupied. Then, during isothermal annealing at 650 or $700^{\circ} \mathrm{C}$, the redistribution between the layers leading to equilibration of trap occupancies was followed as a function of time. The redistribution rate is sensitive to the cavity-trap binding energy as discussed in the preceding section. The starting condition for the isothermal anneals was created by 1) forming the first cavity layer at a depth of $0.7 \mu \mathrm{m}, 2$ ) saturating it with $\mathrm{Cu}$ by heating in the presence of silicide located at $0.1 \mu \mathrm{m}, 3$ ) evaporating the $\mathrm{Cu}$ from the excess silicide by heating for 3 hours at $800^{\circ} \mathrm{C}$, and 4 ) forming the second cavity layer at $0.3 \mu \mathrm{m}$. Figure 4 shows the accumulation of $\mathrm{Cu}$ in the second cavity layer as a function of time at the two temperatures. The curves represent solutions of the diffusiontrapping formalism of Ref. 11 in which the binding energy was adjusted to agree with the data. This procedure yielded $2.2 \pm 0.2 \mathrm{eV}$ expressed relative to $\mathrm{Cu}$ in solution. $\mathrm{Tl}$. binding energy within the cavity traps is thus $\approx 0.5 \mathrm{eV}$ larger than the solution activation energy for $\mathrm{Cu}_{3} \mathrm{Si}$.

A significant issue for the use of cavities as metal-impurity traps is the possibility of 
competition for the binding sites by $\mathrm{H}$, which can be introduced into $\mathrm{Si}$ at various stages of device processing. A previous study determined that the binding energy of $\mathrm{H}$ on cavity surfaces relative to $\mathrm{H}_{2}$ gas is $0.37 \pm 0.1$ $\mathrm{eV}$ [15]. Since the binding energy obtained above for $\mathrm{Cu}$ in cavities relative to $\mathrm{Cu}_{3} \mathrm{Si}$ is $\approx 0.5$ $\mathrm{eV}$, the two quantities differ by substantially less than the combined uncertainties. Hence, whether $\mathrm{Cu}$ from the silicide or $\mathrm{H}$ from $\mathrm{H}_{2}$

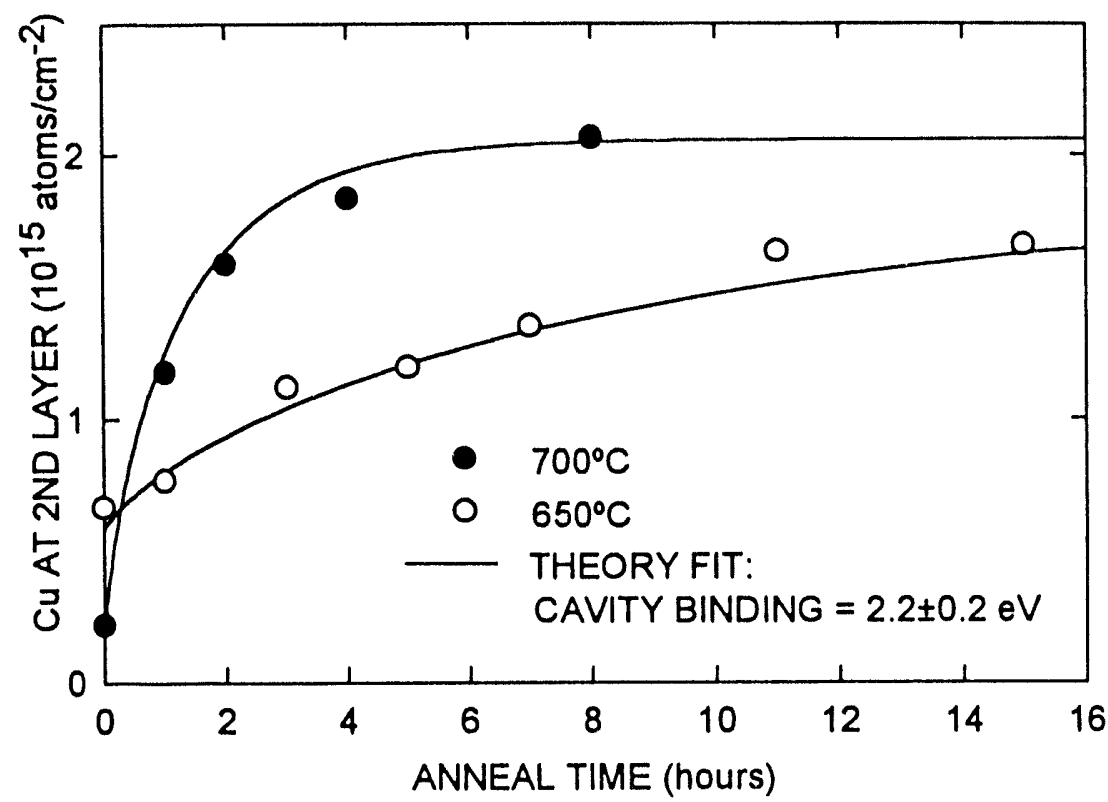

Fig. 4. Redistribution of $\mathrm{Cu}$ from an initially saturated cavity layer to a second, initially unoccupied cavity layer.

gas preferentially occupies the cavity surfaces is not established by information presented to this point. We therefore performed an experiment to observe the competition directly. Cavities were formed by implanting $10^{17} \mathrm{He} / \mathrm{cm}^{2}$ at $30 \mathrm{keV}$ and annealing for $30 \mathrm{~min}$ at $700^{\circ} \mathrm{C}$. The surfaces of these cavities were then saturated with $\mathrm{Cu}$ by heating at $600^{\circ} \mathrm{C}$ in the presence of excess $\mathrm{Cu}_{3} \mathrm{Si}$ on the opposite side of the specimen. The resulting saturation areal density was $5.2 \times 10^{15} \mathrm{Cu} / \mathrm{cm}^{2}$. The specimen was subsequently heated in $\mathrm{H}_{2}$ gas at $600^{\circ} \mathrm{C}$ and a pressure of 650 Torr for 113 hours, a condition previously shown to saturate the walls of initially unoccupied cavities without producing a significant quantity of $\mathrm{H}_{2}$ gas within the open volume [9]. This treatment decreased the $\mathrm{Cu}$ content of the cavities to $0.5 \times 10^{15} \mathrm{~cm}^{-2}$, and $\mathrm{H}$ accumulated in the cavity layer to an areal density of $7.6 \times 10^{15} \mathrm{~cm}^{-2}$. A final vacuum anneal of 1 hour at $800^{\circ} \mathrm{C}$ reduced the $\mathrm{H}$ content by about $90 \%$ and restored the $\mathrm{Cu}$ areal density to $6.4 \times 10^{15} \mathrm{~cm}^{-2}$, indicating reversibility. Thus, $\mathrm{H}$ occupies the cavity-suiface sites in preference to $\mathrm{Cu}$ for these conditions. We hypothesize that the observed replacement of one $\mathrm{Cu}$ atom by more than one $\mathrm{H}$ atom is a consequence of the $\mathrm{Cu}$ undergoing strong chemisorption only on the predominant (111) facets. This is consistent with studies of $\mathrm{Cu}$ on external (111) and (100) surfaces [4,5]. One implication of these results is that $\mathrm{H}$ should be outgassed before using cavities for trapping of metals.

We also performed preliminary experiments on the trapping at $\mathrm{Si}$ cavities of $\mathrm{Ni}$, another technologically important metal impurity. The cavities were formed on one side of a $250 \mu \mathrm{m}$-thick specimen by implanting $10^{17} \mathrm{He} / \mathrm{cm}^{2}$ at $30 \mathrm{keV}$ and annealing at $900^{\circ} \mathrm{C}$ for 1 hour. Nickel was then implanted on the opposite side at $150 \mathrm{keV}$ and a dose of $10^{17} \mathrm{~cm}^{-2}$. The material was subsequently annealed for 89 hours at $550^{\circ} \mathrm{C}$, then for 24 hours at $600^{\circ} \mathrm{C}$, and finally for 16 hours at $700^{\circ} \mathrm{C}$. The time at each temperature was more than sufficient to transfer $10^{16} \mathrm{Ni} / \mathrm{cm}^{2}$ from precipitated silicide across the sample to sinks, based on estimates using published diffusion coefficients and solubilities [13]. The measured areal density of $\mathrm{Ni}$ in the cavity layer was $0.18 \times 10^{15} \mathrm{~cm}^{-2}$ after the first anneal and remained constant during the subsequent heat treatments. We provisionally interpret these results as indicating that $\mathrm{Ni}$, like $\mathrm{Cu}$, is bound more strongly on the cavity walls than in the metal-silicide phase. The greatly reduced saturation areal density for $\mathrm{Ni}$ in the cavity layer - the value is $2.3 \times 10^{15} \mathrm{~cm}^{-2}$ for $\mathrm{Cu}$ under equivalent 
conditions - is tentatively ascribed to the much less dense ordered structure of chemisorbed $\mathrm{Ni}$ on (111) Si. In particular, on external (111) surfaces, ordered chemisorption of $\mathrm{Cu}$ is observed to reach $\approx 1$ monolayer before silicide formation [4], whereas the ordered structure of $\mathrm{Ni}$ is a $\sqrt{ } 19 \times \sqrt{ } 19$ configuration with a maximum coverage of at $1 / 19$ monolayer [6]. On the (100) surface, the tendency for chemisorption is apparently much less for both metals $[5,7]$.

\section{CONCLUSION}

We have shown that two of the detrimental transition-metal impurities in $\mathrm{Si}, \mathrm{Cu}$ and $\mathrm{Ni}$, are trapped by microscopic cavities sufficiently strongly not only to remove atoms from solution but also to dissolve pre-existing silicides. These cavities are thermally stable, surviving heating to temperatures as high as $1180^{\circ} \mathrm{C}$ [16]. Moreover, their formation by $\mathrm{He}$ ion implantation is potentially feasible on the device side as well as the back side of wafers. Because of these properties, cavities are potentially attractive gettering centers for metal impurities in $\mathrm{Si}$.

\section{ACKNOWLEDGMENT}

The authors benefited greatly from discussions with H. J. Stein, J. W. Medernach, P. A. Bennett and R. B. Doak. This work was supported by the United States Department of Energy, Office of Basic Energy Sciences, Division of Materials Sciences, under Contract DE-AC04-94AL85000.

\section{REFERENCES}

1. W. Schröter, M. Seibt, and D. Gilles, in Materials Science and Technology 4: Electronic Structure and Properties of Semiconductors, edited by W. Schröter (VCH Publishers., New York, 1991) pp. 539-589.

2. MRS Bulletin 18, No. 6 (June 1993).

3. T.M. Buck, K.A. Pickar, and J.M. Poate, Appl. Phys. Lett. 21, 485 (1972).

4. D.D. Chambliss and T.N. Rhodin, Phys. Rev. B 42, 1674 (1990), and references therein.

5. H. Kemmann, F. Müller, and H. Neddermeyer, Surf. Sci. 192, 11 (1987).

6. R.J. Wilson and S. Chiang, Phys. Rev. Lett. 58, 2575 (1987).

7. A.E. Dolbak, B.Z. Olshanetsky, S.I. Stenin, and S. A. Teys, Surf. Sci. 218, 37 (1989).

8. C.C Griffioen, J.H. Evans, P.C. de Jong and A. Van Veen, Nucl. Instrum Meth. 27, 417 (1987).

9. S.M. Myers, D.M. Follstaedt, H.J. Stein, and W.R. Wampler, Phys. Rev. B 47, 13380 (1993).

10. D.M. Follstaedt and S.M. Myers, present symposium proceedings.

11. S.M. Myers and D.M. Follstaedt, J. Appl. Phys. 65, 311 (1989).

12. D.M. Follstaedt, Appl. Phys. Lett. 62, 1116 (1993).

13. E.R. Weber, Appl. Phys. A 30, 1 (i983).

14. R.C. Dorward and J.S.Kirkaldy, Trans, Met. Soc. AIME 242, 2055 (1968).

15. W.R. Wampler, S.M. Myers, and D.M. Follstaedt, Phys. Rev. B 48, 4492 (1993).

16. J.W. Medernach (private communication). 


\section{DISCLAIMER}

This report was prepared as an account of work sponsored by an agency of the United States Government. Neither the United States Government nor any agency thereof, nor any of their employees, makes any warranty, express or implied, or assumes any legal liability or responsibility for the accuracy, completeness, or usefulness of any information, apparatus, product, or process disclosed, or represents that its use would not infringe privately owned rights. Reference herein to any specific commercial product, process, or service by trade name, trademark, manufacturer, or otherwise does not necessarily constitute or imply its endorsement, recommendation, or favoring by the United States Government or any agency thereof. The views and opinions of authors expressed herein do not necessarily state or reflect those of the United States Government or any agency thereof. 


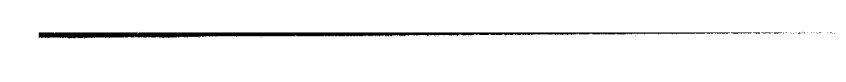

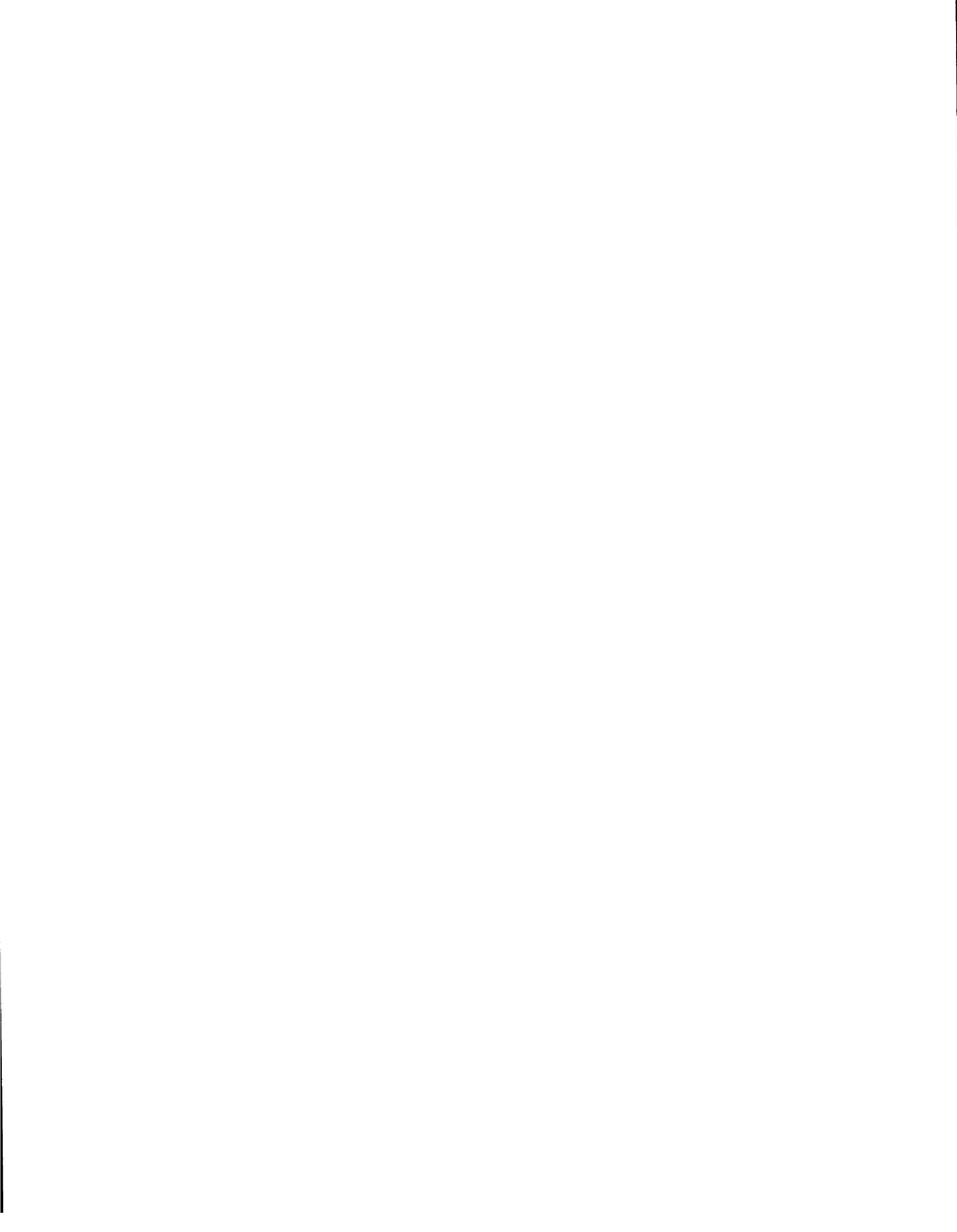

